\title{
Normalized sensitivities and parameter identifiability of in situ diffusion experiments on Callovo-Oxfordian clay at Bure site
}

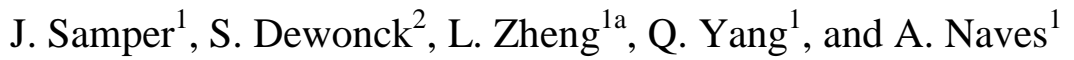 \\ ${ }^{1}$ Universidad de A Coruña. E-15192 A Coruña, Spain. \\ ${ }^{2}$ ANDRA, F-55290 Bure, France \\ a now at: Lawrence Berkeley National Lab, 1 Cyclotron Road, Berkeley, CA, 94720, \\ USA.
}

\begin{abstract}
DIR (Diffusion of Inert and Reactive tracers) is an experimental program performed by ANDRA at Bure underground research laboratory in Meuse/Haute Marne (France) to characterize diffusion and retention of radionuclides in Callovo-Oxfordian (C-Ox) argillite. In situ diffusion experiments were performed in vertical boreholes to determine diffusion and retention parameters of selected radionuclides. C-Ox clay exhibits a mild diffusion anisotropy due to stratification. Interpretation of in situ diffusion experiments is complicated by several non-ideal effects caused by the presence of a sintered filter, a gap between the filter and borehole wall and an excavation disturbed zone (EdZ). The relevance of such non-ideal effects and their impact on estimated clay parameters have been evaluated with numerical sensitivity analyses and synthetic experiments having similar parameters and geometric characteristics as real DIR experiments. Normalized dimensionless sensitivities of tracer concentrations at the test interval have been computed numerically. Tracer concentrations are found to be sensitive to all key parameters. Sensitivities are tracer dependent and vary with time. These sensitivities are useful to identify which are the parameters that can be estimated


with less uncertainty and find the times at which tracer concentrations begin to be sensitive to each parameter. Synthetic experiments generated with prescribed known parameters have been interpreted automatically with INVERSE-CORE ${ }^{2 \mathrm{D}}$ and used to evaluate the relevance of non-ideal effects and ascertain parameter identifiability in the presence of random measurement errors. Identifiability analysis of synthetic experiments reveals that data noise makes difficult the estimation of clay parameters. Parameters of clay and EdZ cannot be estimated simultaneously from noisy data. Models without an EdZ fail to reproduce synthetic data. Proper interpretation of in situ diffusion experiments requires accounting for filter, gap and EdZ. Estimates of the effective diffusion coefficient and the porosity of clay are highly correlated, indicating that these parameters cannot be estimated simultaneously. Accurate estimation of $\mathrm{D}_{\mathrm{e}}$ and porosities of clay and $\mathrm{EdZ}$ is only possible when the standard deviation of random noise is less than 0.01 . Small errors in the volume of the circulation system do not affect clay parameter estimates. Normalized sensitivities as well as the identifiability analysis of synthetic experiments have provided additional insight on inverse estimation of in situ diffusion experiments and will be of great benefit for the interpretation of real DIR in situ diffusion experiments.

Key words: diffusion, retention, numerical model, sensitivity analysis, identifiability analysis, tritium, chloride, CORE

\section{Introduction}

In situ diffusion experiments have been performed at underground research laboratories in clay formations to overcome the limitations of laboratory diffusion experiments and to investigate possible scale effects. Such experiments have been performed in Opalinus clay in Switzerland (Palut et al., 2003; Tevissen et al., 2004; Wersin et al., 2004; 
Van Loon et al., 2004; Yllera et al., 2004; Samper et al., 2006a) and Callovo-Oxfordien clay at Bure in France (Dewonck, 2007; Descostes et al., 2007; Radwan et al., 2005).

ANDRA has undertaken an extensive characterization program at the Bure site to assess the feasibility of a deep high level radioactive waste (HLW) repository in the CallovoOxfordien (C-Ox) clay. DIR (Diffusion of Inert and Reactive tracers) is one of such experimental programs which aims at characterizing diffusion and retention of radionuclides in the clay rock. Various in situ diffusion experiments were performed in vertical boreholes to determine diffusion and retention parameters of selected radionuclides (Dewonck, 2007; Radwan et al., 2005; Descostes et al., 2007). C-Ox clay exhibits a mild diffusion anisotropy due to stratification. Interpretation of in situ diffusion experiments is complicated by several nonideal effects caused by the presence of a sintered filter, a gap between the filter and the borehole wall and an excavation disturbed zone (EdZ) (see Figure 1).

In this paper we evaluate the relevance of such non-ideal effects and their impact on estimated clay parameters by numerical sensitivity analyses and synthetic experiments having similar parameters and geometric characteristics as real DIR in situ diffusion experiments. The paper starts by describing DIR in situ diffusion experiments. Then, numerical methods for their interpretation are presented. A systematic sensitivity analysis performed in terms of normalized sensitivities is also presented after that. Then, the identifiability analysis of tritium and chloride diffusion parameters based on synthetic diffusion experiments is explained. Finally, main conclusions and their relevance for the interpretation of real DIR in situ diffusion experiments are described.

\section{DIR in situ diffusion experiments at Bure site}

Several vertical boreholes were drilled in which in situ diffusion experiments were performed to determine radionuclide diffusion and retention parameters of radioactive tracers. The DIR2001 and DIR2002 experiments were carried out in boreholes drilled from a gallery 
located at $445 \mathrm{~m}$ depth in the Meuse/Haute-Marne underground laboratory. In situ diffusion experiments were performed as single-point dilution tests by injecting tracers into a $1 \mathrm{~m}$ long packed-off section into the boreholes. The required equipment included downhole and surface instrumentation (Palut, 2001). Downhole instrumentation consisted of a pneumatic packer system with a porous screen made of sintered stainless steel mounted just below the packer at the bottom of the borehole. Surface instrumentation included a stainless steel circuit to circulate the water containing the tracers and to allow for injection and sampling of tracers. Tracer activities at the injection section were monitored from $15^{\text {th }}$ March of 2005 to $30^{\text {th }}$ January of 2006. Tritium (HTO), chloride $\left({ }^{36} \mathrm{Cl}^{-}\right)$and iode $\left({ }^{125} \mathrm{I}^{-}\right)$were employed as tracers in DIR 2001, while tritium (HTO), sodium $\left({ }^{22} \mathrm{Na}^{+}\right)$and cesium $\left({ }^{134} \mathrm{Cs}^{+}\right)$were used in DIR 2002. Chloride and iodide are subject to anion exclusion while sodium and cesium undergo sorption. The design of the EST208 experiment differs from that of the DIR 2001 and 2002 experiments because EST208 was performed in a deep borehole drilled from ground surface to a depth of $-542.5 \mathrm{~m}$. Downhole instrumentation consists of a $10 \mathrm{~m}$ long packed diffusion interval with a steel porous filter and two hydraulic lines for flux recirculation. The test equipment includes two circulation systems. One allows circulation from the diffusion chamber to ground surface and the other ensures flow along surface equipment and allows monitoring of geochemical parameters and the extraction of water samples during the experiment. The following tracers were injected in this borehole: tritium (HTO), chloride $\left({ }^{36} \mathrm{Cl}^{-}\right)$and cesium $\left({ }^{134} \mathrm{Cs}^{+}\right)$.

Diffusion in Bure clay exhibits a mild anisotropy due to stratification. Effective diffusion coefficients along horizontal planes are from 1.5 to 2 times larger than vertical effective diffusion coefficients (Dewonck, 2007).

\section{Numerical interpretation of DIR in situ diffusion experiments}


Attempts were made to interpret diffusion experiments using the analytical solution of Cooper et al. (1967) based on the analogy between in situ diffusion experiments and pulse tests (Samper et al., 2007). It was not possible to obtain clay parameters because measured tracer data are affected by a number of factors which are not taken into account by the analytical solution such as the presence of a sintered filter, a gap between the casing and the borehole wall and the excavation disturbed zone (Samper et al., 2007). Given the limitations of the analytical methods, in situ diffusion experiments were interpreted using inverse numerical models.

\subsection{Solute transport equation}

The transport equation for a tracer which diffuses through a low permeability medium is given by (Bear, 1972):

$$
\phi_{a} R \frac{\partial C}{\partial t}=\nabla \cdot\left(\bar{D}_{e} \cdot \nabla C\right)
$$

where $\mathrm{C}$ is the tracer concentration, $\mathrm{t}$ is time, $\phi_{a}$ is the accessible porosity which accounts for anion exclusion and $\mathrm{R}$ is the retardation coefficient defined as

$$
R=1+\frac{\rho K_{d}}{\phi_{a}}
$$

$\mathrm{R}$ is equal to 1 and $\phi_{a}$ is equal to the total porosity if the tracer is not affected by anion exclusion or by adsorption. $\bar{D}_{e}$ is the effective diffusion tensor given by

$$
\bar{D}_{e}=\left(\begin{array}{ccc}
D_{x x} & D_{x y} & D_{x z} \\
D_{y x} & D_{y y} & D_{y z} \\
D_{z x} & D_{z y} & D_{z z}
\end{array}\right)
$$

which can be diagonalized as

$$
\bar{D}_{e}^{\prime}=\left(\begin{array}{ccc}
D_{\xi \xi} & 0 & 0 \\
0 & D_{\eta \eta} & 0 \\
0 & 0 & D_{\zeta \varsigma}
\end{array}\right)
$$


where $D_{\xi \xi}, D_{\eta \eta}$ and $D_{\zeta \zeta}$ are the principal components of the tensor. Components of the effective diffusion tensor in (3) can be calculated from the main components in (4) using equations similar to those of the permeability tensor. Here $D_{\xi \xi}$ and $D_{\eta \eta}$ are horizontal diffusion coefficients parallel to bedding while $D_{\zeta \zeta}$ is the vertical diffusion coefficient.

\subsection{Inverse problem of solute transport and sorption}

The essence of the inverse problem lies on deriving optimum parameter estimates from known concentration data. The optimum parameters are those which minimize an objective function measuring the difference between measured and computed concentrations. Our formulation of the inverse problem is based on a generalized least squares criterion (Sun, 1994; Dai and Samper, 2004). Let $\boldsymbol{p}=\left(\mathrm{p}_{1}, \mathrm{p}_{2}, \mathrm{p}_{3}, \ldots, \mathrm{p}_{\mathrm{M}}\right)$ be the vector of $\mathrm{M}$ unknown parameters. The objective function, $E(\boldsymbol{p})$, can be expressed as:

$$
E(p)=\sum_{i=1}^{N E} W_{i} E_{i}(p)
$$

where $i=1, \ldots, N_{E}$ denotes different types of data, $i=1$ for the water head; $i=2$ for dissolved concentrations; $i=3$ for the total concentration; $i=4$ for the water fluxes; $i=5$ for the water contents in unsaturated media; $\mathrm{i}=6$ for the temperature; and $i=7$ for prior information on model parameters. $W_{\mathrm{i}}$ is the weighting coefficient of the $\mathrm{i}^{\text {th }}$ generalized least-squares criterion, $E_{\mathbf{i}}(\mathrm{p})$, which is defined as

$$
\begin{gathered}
E_{i}(p)=\sum_{l=1}^{L_{i}} w_{l i}{ }^{2} r_{l i}{ }^{2}(p) \\
r_{l i}=u_{l}^{i}(p)-F^{i}{ }_{l}
\end{gathered}
$$

where $u_{l}^{i}(p)$ is the computed value of the $\mathrm{i}^{\text {th }}$ variable at the observation point; the $F^{i}{ }_{l}$ are measured values; $L_{\mathrm{i}}$ is the number of observations, either in space or in time for the $i^{\text {th }}$ type data; and $r_{l i}$ is the residual or difference weighting coefficient for the $l^{\text {th }}$ measurement of the $i^{\text {th }}$ 
type of data. Its value depends on the accuracy of the observations. If some data are judged to be unreliable, they should be assigned very small weights $w_{l i}$ in order to prevent their pernicious effect on the optimization process. Weights for different types of data $W_{\mathrm{i}}$ in (5) are updated automatically during the iterative optimization process as indicated by Dai and Samper (2004). The Gauss-Newton-Levenberg-Marquardt method has been used to minimize the objective function in (5) using the inverse code INVERSE-CORE ${ }^{2 D}$ (Dai and Samper, 1999; 2004). This code can estimate flow and transport parameters and provides statistical measures of goodness-of-fit as well as parameter uncertainties by computing the covariance and correlation matrices, the eigenvalues and approximate confidence intervals (GarcíaGutiérrez et al., 2001; Dai and Samper, 2004; Dai and Samper, 2006; Dai et al., 2006; Samper et al., 2006b).

\subsection{Numerical models}

Numerical interpretation of DIR experiments requires the use of $3 \mathrm{D}$ models due to diffusion anisotropy. However, symmetry with respect to the borehole axis allows the use of 2D axi-symmetric models. The relevance of diffusion anisotropy on tracer evolution at the test interval depends on the ratio between borehole length and tracer penetration. Anisotropy is especially relevant when the length of the testing interval is not much larger than the tracer penetration. Since tracer penetration is clearly much smaller than the tracer diffusion interval for the EST208 experiment, this experiment can be safely interpreted with an 1D axisymmetric model. The relevance of anisotropy for the DIR 2001 and DIR 2002 experiments was unknown a priori and had to be ascertained with a 2D axisymmetric anisotropic numerical model. Thus, 2D finite element models were performed. They account for four material zones: 1) borehole with tracer circulation system, 2) excavation disturbed zone (EdZ), 3) undisturbed clay, and 4) steel plate at the bottom of the borehole. Tracer 
diffusion parameters for the undisturbed clay and the EdZ were derived from available data from laboratory experiments (Dewonck, 2007; Radwan et al., 2005; Descostes et al., 2007). The results of experiment simulations show that penetration of all tracers is much smaller than the length of the tracer interval. Concentrations at the testing interval computed with 1D and 2D models are completely similar and are not sensitive to the anisotropy of the effective diffusion coefficient. Therefore, a 1D axisymmetric model was used to simulate the DIR in situ diffusion experiments.

The injection section is composed of an empty central steel cylinder and a $3 \mathrm{~mm}$ thick steel filter between which the fluid containing the tracer cocktail circulates. There is a gap of $3 \mathrm{~mm}$ between the filter and the borehole wall. This gap is initially filled with artificial water injected during the hydraulic equilibration period. Later on, water in contact with argillite forms possibly a viscous mud. Both, this gap and the filter were taken into account in the model. Therefore five material zones were considered: the injection zone, the filter, the gap, a $2 \mathrm{~cm}$ thick EdZ and the undisturbed C-Ox clay.

Models of in situ diffusion experiments usually consider the borehole, the geological formation and, sometimes, an EdZ. They rarely take into account filters and gaps. Previous studies indicate that tracer dilution curves of in situ DIR experiments cannot be reproduced unless an EdZ is considered (Radwan et al., 2005; Descostes et al., 2007; Samper et al., 2007). The effect of a sintered filter and a gap has been analyzed here by comparing concentrations computed with a detailed model which accounts for filter and gap with those computed with a simplified model which has only three material zones: the borehole, the EdZ and the undisturbed clay. Although patterns of time evolution of the tracer concentration in the tracer interval, the EdZ and the undisturbed clay are similar for both models, there are some differences which are small for HTO and noticeable for tracers that are subject to anion exclusion or sorption (see Figure 2). The simplified model overestimates chloride and iodide 
concentrations in the tracer interval. However, for cesium the tracer concentrations in the tracer intervals are underestimated during the first 4 days and then they are overestimated (see Figure 2). In summary, failing to account for the filter and the gap may result in significant errors in tracer concentrations and in turn may lead to biased estimates of tracer parameters.

Values of the effective diffusion coefficient, the accessible porosity and the distribution coefficient of each tracer in $\mathrm{C}-\mathrm{Ox}$ clay were derived from available through-diffusion laboratory experiments (see Table 1). An anisotropy ratio of 1.56 was considered. The distribution coefficient, $\mathrm{K}_{\mathrm{d}}$, for ${ }^{22} \mathrm{Na}^{+}$in $\mathrm{C}-\mathrm{Ox}$ clay is assumed to be equal to $0.74 \mathrm{ml} / \mathrm{g}$ (Radwan et al., 2005). For ${ }^{134} \mathrm{Cs}^{+}$a $\mathrm{K}_{\mathrm{d}}$ of $50 \mathrm{ml} / \mathrm{g}$ was used. Effective diffusion coefficients for other materials were derived from those of undisturbed clay by adopting an Archie's law with an exponent equal to 4/3. The filter porosity was 0.3 (Dewonck, 2007). On the other hand, porosities of EdZ and gap are unknown. As an educated guess, the porosity of the EdZ was assumed to be twice that of clay while the porosity of the gap was assumed to be 0.6. The undisturbed clay and the EdZ were assumed to have the same distribution coefficient.

\section{Sensitivity analysis}

A model always entails simplifications of the real system. Model results depend on parameters that may contain uncertainties. Since parameter estimation errors are related to sensitivities of concentrations to changes in parameters, a detailed sensitivity analysis was performed to evaluate parameter uncertainties. For each tracer, its dilution curve was computed first for a set of tracer reference parameters. With these reference parameters, sensitivity runs were performed by changing relevant parameters one-at-a-time within prescribed ranges. Such sensitivities were evaluated for all tracers and the following parameters: 1) Effective diffusion coefficient of the filter, 2) Porosity of the gap, 3) Effective diffusion coefficient and accessible porosity of the EdZ, 4) Effective diffusion coefficient and 
accessible porosity of undisturbed clay, 5) Distribution coefficient, 6) Thickness of EdZ and 7) Volume of the injection system.

Since model parameters have different units and vary over different ranges of values, their sensitivities cannot be compared directly. In order to compare sensitivities of concentrations to changes in different parameters, relative sensitivities, $R S$, have been used. Such sensitivities are defined as the ratio between relative changes in concentrations and relative changes in parameters, $\Delta P$, which are defined as parameter changes with respect to reference values, $P_{b}$ :

$$
\Delta P(\%)=\frac{\left|P_{S}-P_{b}\right|}{P_{b}} \times 100
$$

where $\mid$ denotes the absolute value and $P_{s}$ is the parameter value chosen for the sensitivity analysis. Relative sensitivity is computed as the ratio between the relative change in concentration and the relative change in parameter:

$$
\Delta C(\%)=\frac{\left|C_{S}-C_{b}\right|}{C_{b}} \times 100
$$

where $C_{b}$ and $C_{s}$ are computed concentrations for base and sensitivity runs, respectively.

$$
R S=\frac{\Delta C}{\Delta P}
$$

Calculated $R S$ for each tracer are listed in Table 2. It should be noticed that relative sensitivities are dimensionless and therefore relative sensitivities corresponding to different parameters can be compared directly.

Largest relative sensitivities correspond to a decrease in the volume of the circulation system. Such sensitivities range from 0.45 for HTO to 1.09 for ${ }^{134} \mathrm{Cs}^{+}$in the DIR2002 experiment. Therefore, the volume of the circulation system is a key parameter affecting the tracer dilution in the testing interval. 
Variations in EdZ thickness affect significantly all tracers. It should be noticed that the tracer concentrations are more sensitive to a decrease (from 2 to $0 \mathrm{~cm}$ ) than to an increase (from 2 to $4 \mathrm{~cm}$ ) of the EdZ thickness. This is especially true for sorbing tracers.

Sensitivities to diffusion and sorption parameters are different for different tracers. HTO is more sensitive to the EdZ porosity and the $\mathrm{D}_{\mathrm{e}}$ of clay and EdZ. Iodide, however, is more sensitive to EdZ parameters. The influence of EdZ parameters is largest for chloride concentrations which are also sensitive to the gap porosity.

Relative sensitivities for ${ }^{36} \mathrm{Cl}^{-}$and ${ }^{125} \mathrm{I}^{-}$are similar. They are generally smaller than those of other tracers. Therefore, it can be concluded that ${ }^{36} \mathrm{Cl}^{-}$and ${ }^{125} \mathrm{I}^{-}$parameters are the most difficult ones to estimate.

Relative sensitivities of ${ }^{22} \mathrm{Na}^{+}$attain values which are between those of HTO and ${ }^{134} \mathrm{Cs}^{+}$. Sodium is the most sensitive tracer to changes in $K_{d}$ and $D_{e}$ of EdZ. This tracer is also sensitive to the $\mathrm{D}_{\mathrm{e}}$ of clay and filter.

Cesium concentrations are very sensitive to changes in the $D_{e}$ of the filter, the $K_{d}$ and parameters of the EdZ. On the other hand, sodium and cesium lack sensitivity to clay parameters.

Relative sensitivities of a given tracer such as ${ }^{134} \mathrm{Cs}^{+}$are similar in all experiments in which such a tracer is used (see Table 2).

Sensitivities of tracer concentrations to changes in parameters vary with time. Changes in $\mathrm{D}_{\mathrm{e}}$ of undisturbed clay affect tracer dilution curves after some time (Figure 3). Early time concentrations are not affected by changes in $\mathrm{D}_{\mathrm{e}}$. Times at which curves are sensitive to changes in $D_{e}$ depend on the tracer. For instance, HTO data begin to be sensitive to $D_{e}$ after 20 days while those of sodium are sensitive after 45 days. ${ }^{125} \mathrm{I}^{-}$concentrations start to be sensitive to $D_{e}$ after more than 100 days. These times at which tracer concentrations start to be sensitive to $D_{e}$ are inversely proportional to tracer penetration depths. This depth is largest for 
HTO and smallest for ${ }^{134} \mathrm{Cs}^{+}$. Sorption of ${ }^{134} \mathrm{Cs}^{+}$so strong that its concentration in the tracer interval is not sensitive to changes in $\mathrm{D}_{\mathrm{e}}$ by a factor of 0.5 and 2 (Figure 3 ).

Sensitivities of tracer dilution curves to changes in clay accessible porosity are qualitatively similar to those of clay $\mathrm{D}_{\mathrm{e}}$ (not shown here). Both early and late time tracer data lack sensitivity to clay porosity. Only tracer data at intermediate times are sensitive to porosity.

The sensitivity of tracer dilution curves to changes in $\mathrm{D}_{\mathrm{e}}$ of the EdZ also depends on time (Figure 4). Times at which curves are sensitive to changes in $D_{e}$ of the $E d Z$ are smaller than those corresponding to the $\mathrm{D}_{\mathrm{e}}$ of clay (compare Figures 3 and 4). Concentrations are sensitive to changes in $\mathrm{D}_{\mathrm{e}}$ of EdZ after 3 days for HTO and ${ }^{22} \mathrm{Na}^{+}$and after 20 days for I. These times coincide approximately with the times needed for tracers to diffuse through filter and gap.

All dilution curves are sensitive to changes in $\mathrm{D}_{\mathrm{e}}$ of gap and filter. Changes in any of these parameters affect sorbing tracers more strongly than conservative tracers. Dilution curves are sensitive to such changes from the beginning of the experiment (Figure 5).

Sensitivities of ${ }^{22} \mathrm{Na}^{+}$and ${ }^{134} \mathrm{Cs}^{+}$concentrations to changes in $\mathrm{K}_{\mathrm{d}}$ by factors of 0.5 and 2 are remarkable (Figure 6). Tracer concentrations at the injection zone begin to be sensitive after approx 1 day. The largest sensitivity is achieved from 20 to 100 days for ${ }^{22} \mathrm{Na}^{+}$and from 3 to 20 days for ${ }^{134} \mathrm{Cs}^{+}$. For a reliable estimation of $\mathrm{K}_{\mathrm{d}}$, the tracer sampling frequency should be intensified during time periods at which tracer concentrations are most sensitive to $K_{d}$.

\section{Identifiability analysis}

\subsection{Methodology}

Synthetic data have been generated in order to provide insight on inverse estimation of diffusion and sorption experiments and to study parameter identifiably. Synthetic diffusion experiments having the same geometric properties as real experiments have been simulated 
numerically for reference values of diffusion and sorption parameters. Synthetic concentration data have then been used to estimate parameters. Since true values are known, one can clearly identify which parameter can be estimated and how reliable these estimates really are. The difference between the estimation of real and synthetic experiments is that in real experiments true parameters are unknown while in synthetic experiments they are known.

Synthetic experiments are often used to study parameter identifiability and parameter uncertainties (Carrera et al., 1989). The procedure for performing the identifiably study with synthetic data involves the following steps: 1) Generating synthetic data from a forward run of the numerical model; 2) Adding multiplicative random noise to synthetic data with increasing standard deviations ranging from 0 to 0.05 , a value similar to that of noise of actual data from the DIR experiments (Samper et al., 2007); 3) Estimating key diffusion parameters from noisy synthetic data in several stages, starting first with the estimation of $D_{e}$ and accessible porosity, $\Phi_{a c c}$ of clay, followed by the estimation of the EdZ parameters and ending with estimating of all four parameters simultaneously; 4) Evaluating uncertainties caused by uncertainties in EdZ existence and thickness, the values of the volume of water in the injection system, the effective diffusion coefficient of the filter and of the porosity of the gap.

\subsection{Results for HTO}

Table 3 summarizes results of the identifiability analysis for HTO. Estimation runs have been performed considering different initial starting values of parameters and standard deviations of synthetic data.

When only the diffusion coefficient of clay is estimated, estimated values are close to the true value $\left(4.05 \cdot 10^{-11} \mathrm{~m}^{2} / \mathrm{s}\right)$ even for a standard deviation of noise of 0.1 . It can be seen that noise in the HTO data introduces a bias in $\mathrm{D}_{\mathrm{e}}$ estimates which for a standard deviation of $5 \%$ is smaller than $5 \%$ and for a standard deviation of $10 \%$ is about $10 \%$. 
On the other hand, poor estimates of $\mathrm{D}_{\mathrm{e}}$ and $\Phi_{a c c}$ are obtained for noisy data when they are estimated simultaneously. Since clay $D_{e}$ and $\Phi_{a c c}$ are highly correlated $(\rho=-0.99)$, they cannot be estimated simultaneously when the data have noise.

When $\mathrm{D}_{\mathrm{e}}$ and $\Phi_{a c c}$ of the EdZ are estimated, it is found that they are strongly correlated (-0.91) and therefore cannot be estimated properly when the data have noise.

Joint estimation of effective diffusion coefficients of clay and EdZ as well as porosities of clay and EdZ is only possible when the data have no noise. Parameter estimates are strongly correlated. Their correlation coefficients are close to either +1 or -1 . Estimates are close to true values when the standard deviation of noise is 0 or 0.01 . However, when the standard deviation of noise is 0.05 , the parameter estimates depend on initial values.

It is well known that prior information on parameters can greatly improve the estimation process (Dai and Samper, 2004). The role of prior information on parameter estimation of DIR experiments has been evaluated with a set on runs in which $\mathrm{D}_{\mathrm{e}}$ and $\Phi_{\text {acc }}$ in clay were estimated. Prior information for each parameter was set equal to its true value. Different weights were tested for prior information. For large weights of prior information, estimates are close to prior information, and consequently, a small value of the objective function is obtained. It should be noticed, however, that the objective function reaches nearly a constant value for weights larger than 1.5 (Figure 7).

Poor estimates are obtained when all four parameters are estimated simultaneously when data have noise, even if parameter prior information for the clay formation is available.

A set of runs has been performed assuming no EdZ (see Table 4). Since $\mathrm{D}_{\mathrm{e}}$ and $\Phi_{a c c}$ of the EdZ are larger than those of undisturbed clay, estimated values of $\mathrm{D}_{\mathrm{e}}$ and $\Phi_{a c c}$ are larger than reference values when the thickness of the EdZ is 0. Acceptable estimates are obtained when $\mathrm{D}_{\mathrm{e}}$ and $\Phi_{a c c}$ are estimated separately by starting with large initial values. However, the inverse algorithm stops at local minima with suboptimal parameter estimates when the initial 
values are smaller than the reference values. Clearly, synthetic data cannot be fit with a model without EdZ.

Uncertainties caused by possible errors in the volume of water in the injection system have been evaluated by estimating clay diffusion parameter for volumes from 5 to $10 \%$ smaller than the true value. Errors of 5 to $10 \%$ in the volume of water of the system do not have a large effect on the clay $D_{e}$, but introduce a marked bias in the clay porosity (see Table 4).

An increase of the gap porosity from 0.6 (reference value) to 1 causes a small, but noticeable deviation from the synthetic data (Figure 8). In order to compensate for the change in the gap porosity, diffusion coefficients and porosities of clay and EdZ have to change. The optimum fit is achieved with porosities slightly larger than the reference values and with effective diffusion coefficients slightly smaller than the reference values. The inverse algorithm converges to local minima when the estimation starts at values either larger or smaller than the reference values (see Table 4). This means that errors in the porosity of the gap lead to errors in the estimation of tracer diffusion parameters.

If the $D_{e}$ of the filter is taken to be twice its reference value, an optimum fit is achieved with porosities slightly larger and effective diffusion coefficients slightly smaller than the reference values (Figure 9). The smallest value of the objective function is obtained when estimation starts at reference values. The inverse algorithm converges to local minima when the estimation starts at values either larger or smaller than the reference values. Therefore, the $D_{e}$ value of the filter is a key parameter for estimating tracer diffusion parameters too.

\subsection{Results for chloride}

Identifiability analysis for chloride has been performed similar to that of HTO. Estimates of effective diffusion coefficients and accessible porosities in clay and EdZ are summarized in Table 5. $\mathrm{D}_{\mathrm{e}}$ and $\Phi_{a c c}$ of ${ }^{36} \mathrm{Cl}^{-}$in clay can be estimated accurately when the data 
are free of noise $(\sigma=0)$. When data include noise, the estimated $\Phi_{a c c}$ reaches either its lower or upper bound no matter what the initial guess was. Therefore, it can be concluded that these two parameters cannot be estimated at the same time because they are strongly correlated $(\rho=-0.99)$. Estimates of EdZ parameters are excellent if $\sigma=0$ and are acceptable for $\sigma=0.02$ and 0.05 . A similar conclusion is reached when the $\mathrm{D}_{\mathrm{e}}$ value of clay and $\mathrm{EdZ}$ are estimated simultaneously. These two parameters can be properly estimated simultaneously, because their correlation coefficient is not large $(\rho=-0.76)$. Results of runs in which accessible porosities of clay and EdZ are estimated show that estimated values coincide with true values for $\sigma=0$ and are close to true values for noisy data even though the correlation between these two parameters is significant $(\rho=-0.86)$.

When four parameters are estimated at the same time, estimates coincide with true values for $\sigma=0$. However, for $\sigma=0.02$ parameter estimates are poor and depend on the initial values.

$\mathrm{D}_{\mathrm{e}}$ and $\Phi_{a c c}$ of clay cannot be estimated simultaneously when it is assumed that there is no EdZ (Figure 10). Estimated values are out of the parameter range regardless the initial guess (Table 6). Both parameters have been estimated in the case when the volume of water in the circulation system is $5 \%$ smaller than the true value. There are no differences between estimated and true values for $\sigma=0$. However, estimates for data having noise $(\sigma=0.02)$ depend on initial values.

Clay diffusion parameters were estimated for a gap porosity of 1 . In general, parameter estimates are not close to true values. When initial values are larger than true values, the estimated effective diffusion coefficient is acceptable. However, the estimated accessible porosity then reaches a local minimum. Therefore, uncertainties in the porosity of the gap affect strongly the estimation of the clay porosity and to a less extent the diffusion coefficient of the clay. 
Identifiability runs performed using a $D_{e}$ value of the filter of twice its true value show that parameter estimates deviate from true values even though the fit to synthetic data is good. Estimates of $D_{e}$ are similar in all cases regardless the initial parameter values or data noise and estimates of the clay porosity reach always lower or upper bounds. Therefore, it can be concluded that uncertainties in the $\mathrm{D}_{\mathrm{e}}$ values of filter affect strongly the estimation of the clay porosity and to a less extent the diffusion coefficient of clay for ${ }^{36} \mathrm{Cl}^{-}$.

\section{Conclusions and relevance for real diffusion experiments}

Interpretation of the DIR in situ diffusion experiments performed at Bure site on C-Ox clay is complicated by several non-ideal effects caused by the presence of a sintered filter, a gap between the filter and the borehole wall and an excavation disturbed zone (EdZ). The relevance of such non-ideal effects and their impact on estimated clay parameters have been evaluated with numerical sensitivity analyses and synthetic experiments.

Model results indicate that DIR in situ diffusion experiments can be safely interpreted with a simple $1 \mathrm{D}$ axisymmetric model because tracer dilution curves are not sensitive to diffusion anisotropy.

The effect of filter and gap has been analyzed by comparing tracer dilution curves with detailed and simplified models. Model results indicate that failing to account for filter and gap may result in significant errors in tracer concentrations.

Normalized dimensionless sensitivities of tracer concentrations at the test interval have been computed numerically. Tracer concentrations are sensitive to all key parameters. Their sensitivities are tracer dependent and vary with time. Sensitivities have been used to identify parameters that can be estimated with less uncertainty. Times at which tracer concentrations begin to be sensitive to each parameter have been identified. 
Synthetic experiments generated with predefined parameters have been interpreted automatically with INVERSE-CORE ${ }^{2 \mathrm{D}}$ and then used to evaluate the relevance of non-ideal effects and to ascertain parameter identifiability for $\mathrm{HTO}$ and ${ }^{36} \mathrm{Cl}^{-}$in the presence of random measurement errors. Identifiability analysis of synthetic experiments reveals that data noise makes the estimation of clay parameters difficult. Parameters of clay and EdZ cannot be estimated simultaneously when the data contain noise. Models without an EdZ fail to reproduce synthetic data. Proper interpretation of in situ diffusion experiments requires accounting for filter, gap and EdZ. Estimates of the effective diffusion coefficient and of the porosity of clay are highly correlated, indicating that these parameters cannot be estimated simultaneously. Accurate estimation of $\mathrm{D}_{\mathrm{e}}$ values and porosities of clay and EdZ is only possible when the standard deviation of random noise is less than 0.01. Small errors in volume of the circulation system do not affect clay parameter estimates.

Normalized sensitivities, transient tracer sensitivities to parameters as well as conclusions of identifiability analysis will be most useful for calibration and interpretation of real DIR in situ diffusion experiments (see Samper et al., 2007).

\section{Acknowledgment}

Work described in this paper was partly funded through Contract No. DE-AC02-05CH11231 with the U.S. Department of Energy.

\section{References}

Bear, J., 1972. Dynamics of fluids in porous media. Elsevier, New York.

Carrera, J., Neuman, S.P., 1986. Estimation of aquifer parameters under steady-state and transient conditions: background and statistical framework. Water Resour. Res. 22 (2), 199-210. 
Carrera, J., Samper, J., Vives, L., Kulhman, U., 1989. Automatic inverse methods for the analysis of four pulse tests at the Leuggern borehole. NAGRA NTB 88-34.

Cooper, H.H., Bredehoeft, J.D., Papadopoulus, I.S., 1967. Response of a finite diameter well to an instantaneous charge of water. Water Resour. Res. 3(1), 263-269.

Dai, Z., Samper, J., 1999. INVERSE-CORE ${ }^{2 \mathrm{D}}$ : A code for the inverse problem of water flow and reactive solute transport, Users Manual, Version 0. University of La Coruña.

Dai, Z., Samper, J., 2004. Inverse problem of multicomponent reactive chemical transport in porous media: Formulation and Applications. Water Resour. Res. 40, W07407, doi:10.1029/2004WR003248.

Dai Z., Samper, J., 2006. Inverse modeling of water flow and multicomponent reactive transport in coastal aquifer systems. J. Hydrol. 327(3-4), 447-461.

Dai Z., Samper, J., Ritzi, R., 2006. Identifying geochemical processes by inverse modeling of multicomponent reactive transport in Aquia aquifer. Geosphere, Vol. 4, No 4, 210-219.

Descostes M., Radwan J., Blin V., Tevissen E., 2007. Rapport de suivi scientifique II Expérience DIR - Analyses en actif et conception associée. ANDRA report D.RP.17CEA06-014.

Dewonck, S. 2007. Expérimentation DIR. Synthese des résultats obtenus au 01/03/07. Laboratoire de recherche souterrain de Meuse/Haute-Marne. ANDRA report D.RP.ALS.07-0044.

García-Gutiérrez, M., T. Missana, M. Mingarro, J. Samper, Z. Dai \& J. Molinero, 2001 Solute transport properties of compacted Ca-bentonite used in FEBEX project, J Cont Hydrol. Vol. 47, nº 2-4, 127-137.

Palut, J.M., 2001. Spécifications générales - Expérimentation DIR - Essai de Diffusion de Traceurs Inertes et Réactifs. Rapport Andra D.SP.ADPE.01.097. 
Palut, J.M., Montarnal, P., Gautschi, A., Tevissen, E., Mouche, E., 2003. Characterisation of HTO diffusion properties by an in situ tracer experiment in Opalinus clay at Mont Terri. J. Cont Hydrol. 61(1), 203-218.

Radwan, J., Tevissen, E., Descostes, M., Blin, V., 2005. Premiers éléments d'interprétation et de modélisation des expériences de diffusion de traceurs inertes et réactifs en laboratoire souterrain de Meuse / Haute-Marne. Note technique CEA NTDPC/SECR 05-046/A.

Samper, J., C. Yang, A. Naves, A Yllera, A. Hernández, J. Molinero, J. M. Soler, P. Hernán, J.C. Mayor and J. Astudillo, 2006a, A fully 3-D anisotropic model of DI-B in situ diffusion experiment in the Opalinus clay formation, Phy. and Chem. Earth, 31, 531-540.

Samper, J., Dai, Z., Molinero, J., García-Gutiérrez, M., Missana, T., Mingarro, M., 2006b. Interpretation of solute transport experiments in compacted Ca-bentonites using inverse modelling. Physics and Chemistry of the Earth 31, 640-648.

Samper, F.J., Zheng, L., Yang, Q., Naves, A., Yang, C., 2007. Modeling and numerical interpretation of in situ DIR diffusion experiments on C-Ox Clay at Bure site (Phase 1). Final Report. Universidade da Coruña. Spain.

Sun, N.Z., 1994. Inverse Problems in Groundwater Modeling. Kluwer Academic Publishers, Netherlands, 364 pp.

Tevissen E., Soler, J. M., Montarnal P., Gautschi A. and Van Loon L.R., 2004, Comparison between in situ and laboratory diffusion studies of HTO and halides in Opalinus clay from the Mont Terri, Radiochim. Acta 92, 781-786.

Van Loon, L.R., Wersin , P., Soler J.M., Eikenberg, J., Gimmi, Th., Hernán, P., Dewonck, S., and Savoye, S., 2004 In-situ diffusion of HTO, ${ }^{22} \mathrm{Na}^{+}, \mathrm{Cs}^{+}$and $\mathrm{I}^{-}$in Opalinus clay at the Mont Terri underground rock laboratory, Radiochim. Acta, 92, 757-763.

Wersin, P., Van Loon, L. R., Soler, J., Yllera, A., Eikenberg, J., Gimmi, T., Hernan, P., Boisson, J.-Y, 2004. Long-term Diffusion Experiment at Mont Terri: First Results from Field and Laboratory Data. Appl. Clay Sci. 26, 123-135. 
Yllera, A., Hernández, A., Mingarro, M., Quejido, A., Sedano, L.A., Soler, J.M., Samper, J., Molinero, J., Barcala, J.M., Martín, P.L., Fernández, M., Wersin, P., Rivas, P., Hernán, P., 2004. DI-B experiment: planning, design and performance of an in situ diffusion experiment in the Opalinus clay formation. Appl. Clay Sci. 26, 181-196. 


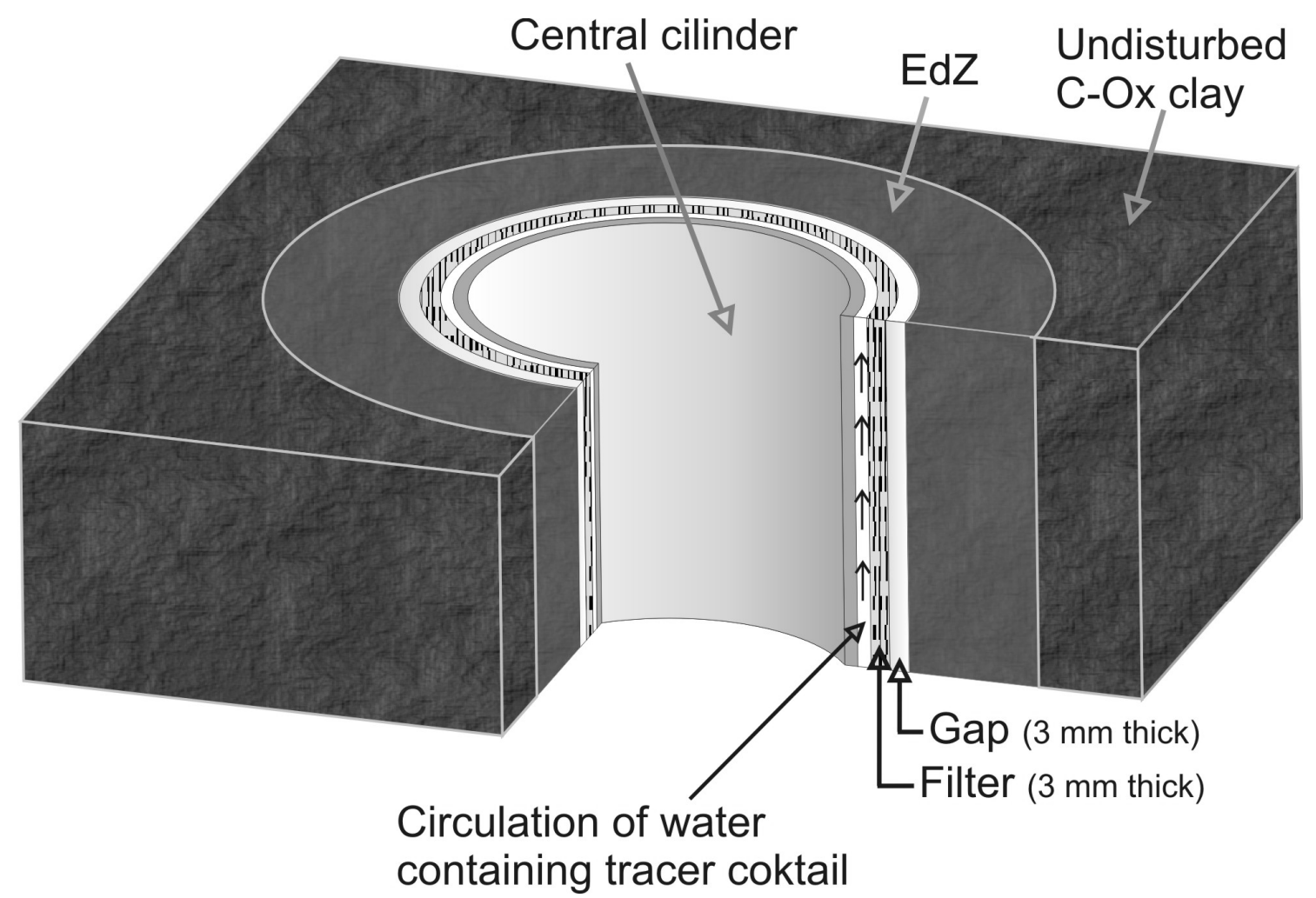

Figure 1. Sketch of borehole geometry for DIR experiments. 




C/Co

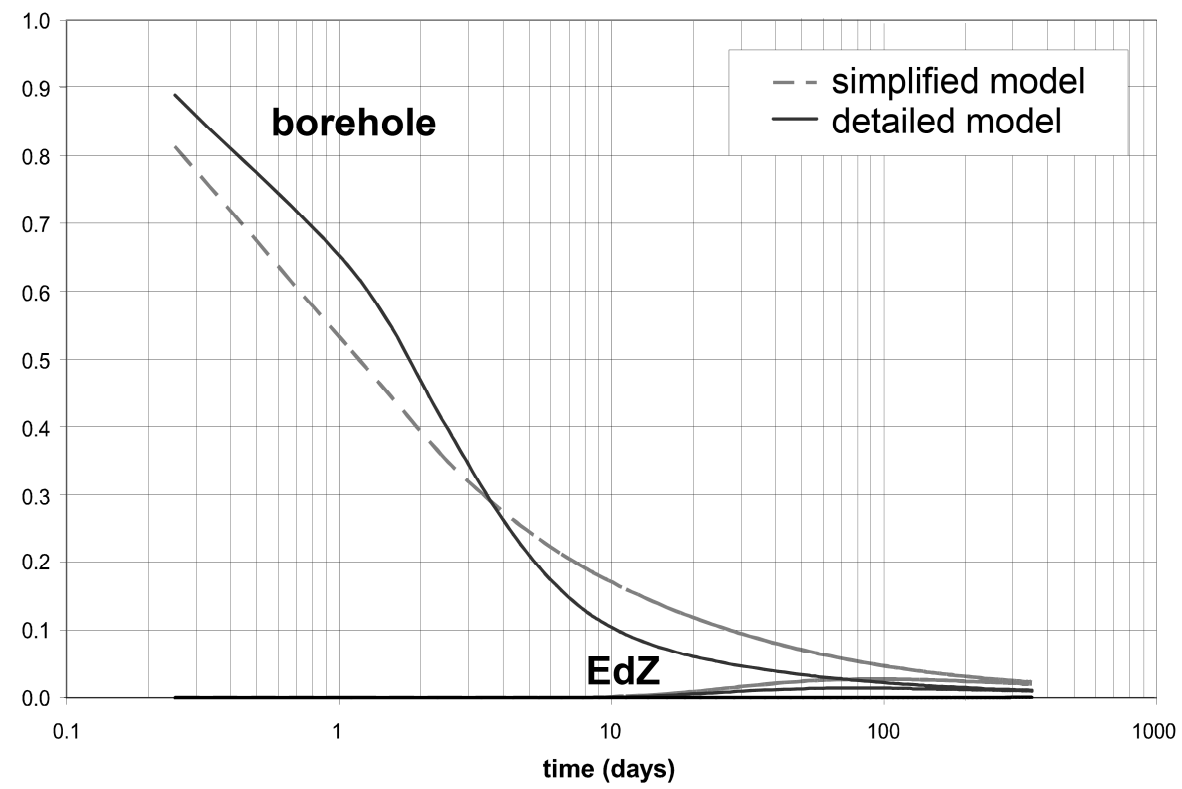

Figure 2. Time evolution of ${ }^{36} \mathrm{Cl}^{-}$(top) and ${ }^{134} \mathrm{Cs}^{+}$(bottom) concentrations in borehole, EdZ and undisturbed clay for the DIR2001 experiment computed with detailed (solid lines) and simplified (dashed lines) models. 
$\mathrm{C} / \mathrm{Co}$

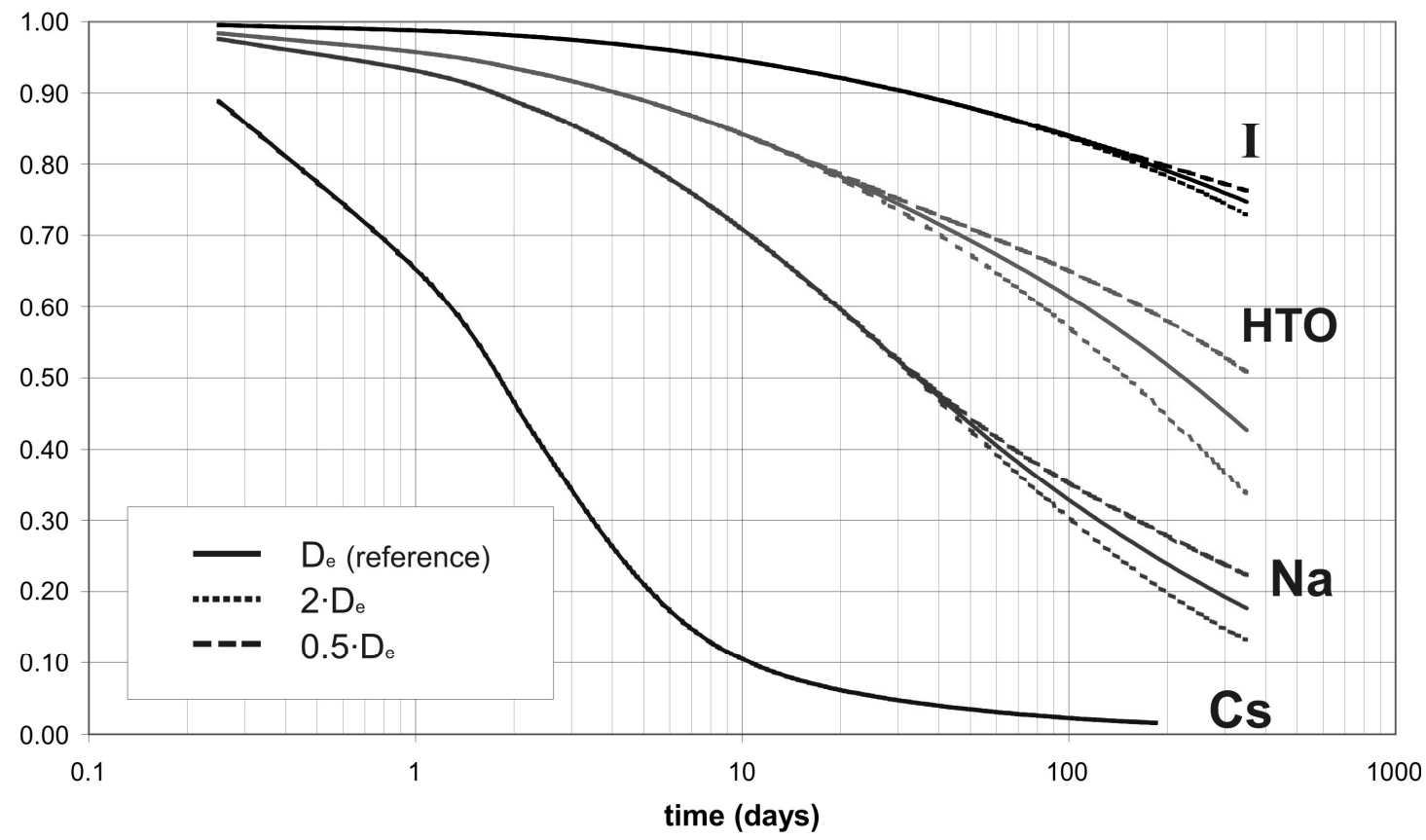

Figure 3. Sensitivity of tracer concentrations in the injection zone to changes in $\mathrm{D}_{\mathrm{e}}$ of clay.

C/Co

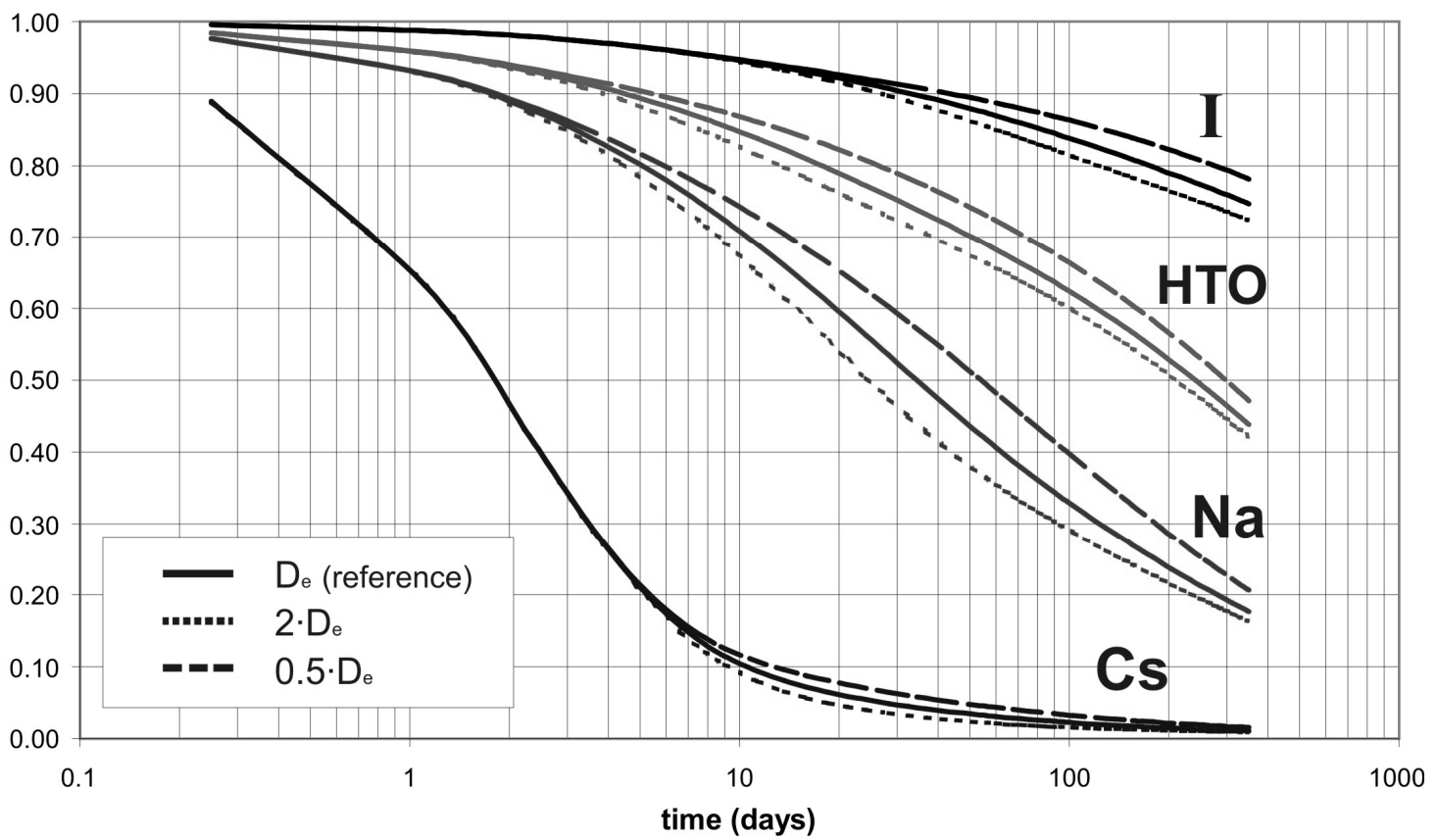

Figure 4. Sensitivity of tracer concentrations in the injection zone to changes in $\mathrm{D}_{\mathrm{e}}$ of EdZ. 
$\mathrm{C} / \mathrm{Co}$

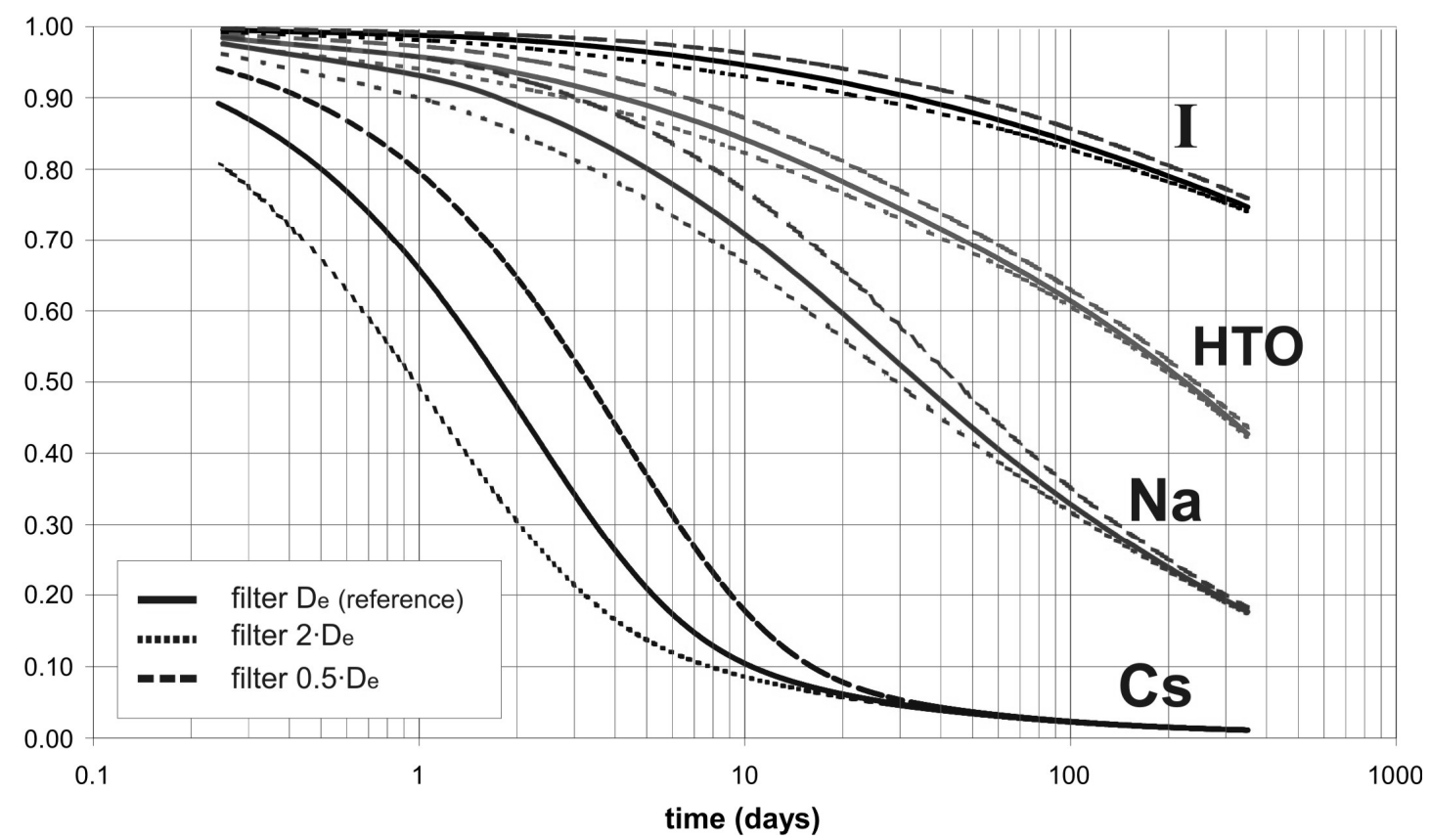

Figure 5. Sensitivity of concentrations in the injection zone to variation in $D_{\mathrm{e}}$ of filter.

$\mathrm{C} / \mathrm{Co}$

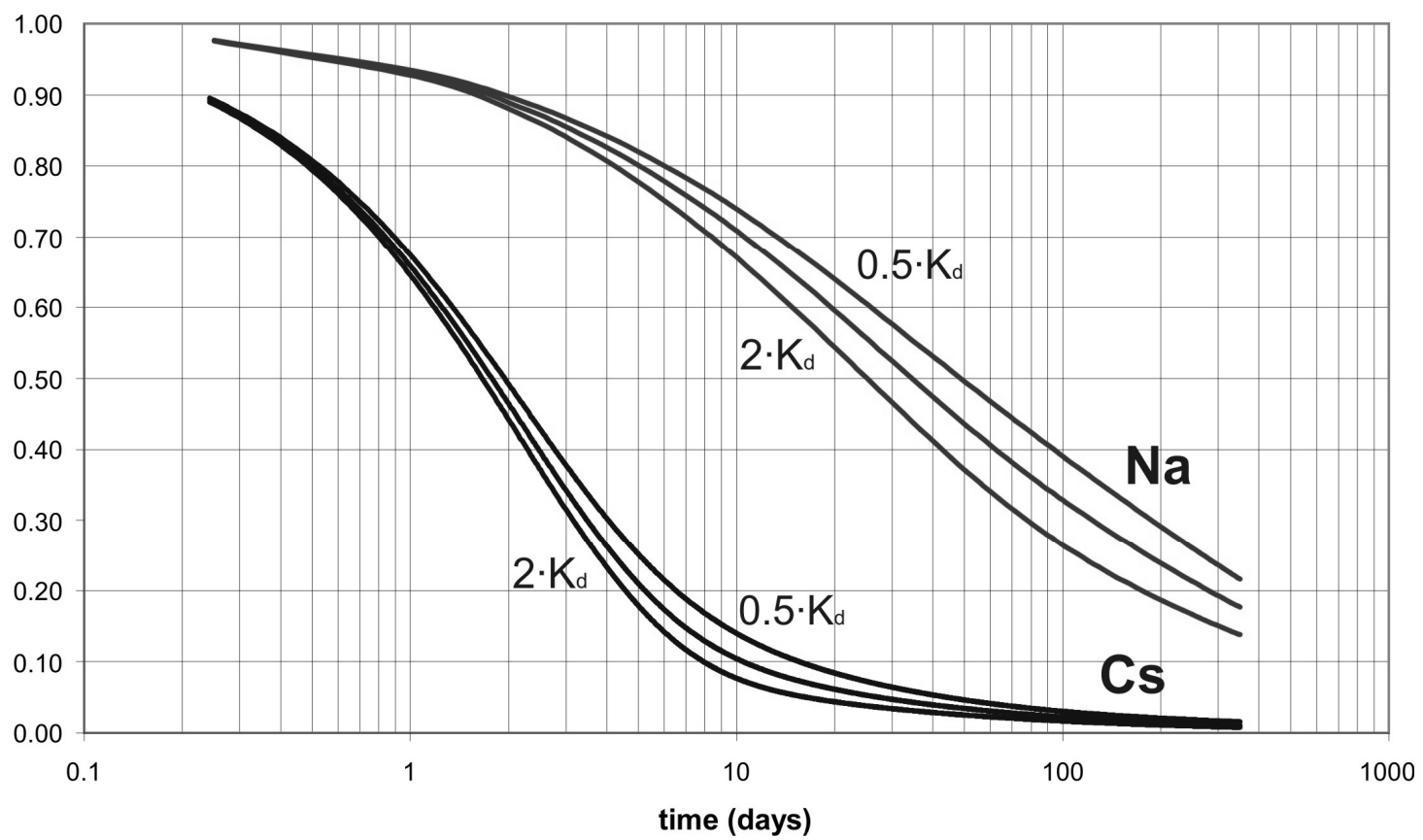

Figure 6. Sensitivity of concentrations in the injection zone to variation in $\mathrm{K}_{\mathrm{d}}$ of clay. 


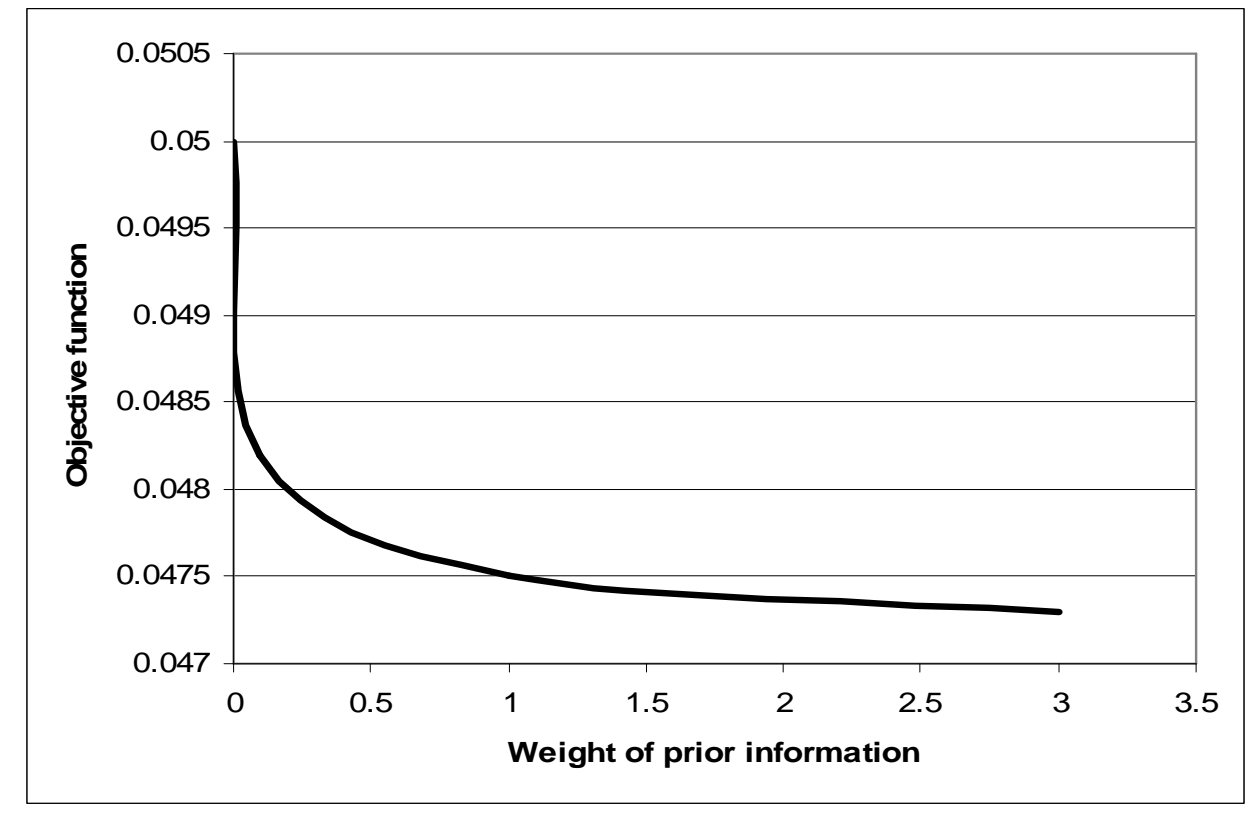

Figure 7. Variation of objective function with the weight given to prior information.

\section{$\mathrm{C} / \mathrm{Co}$}

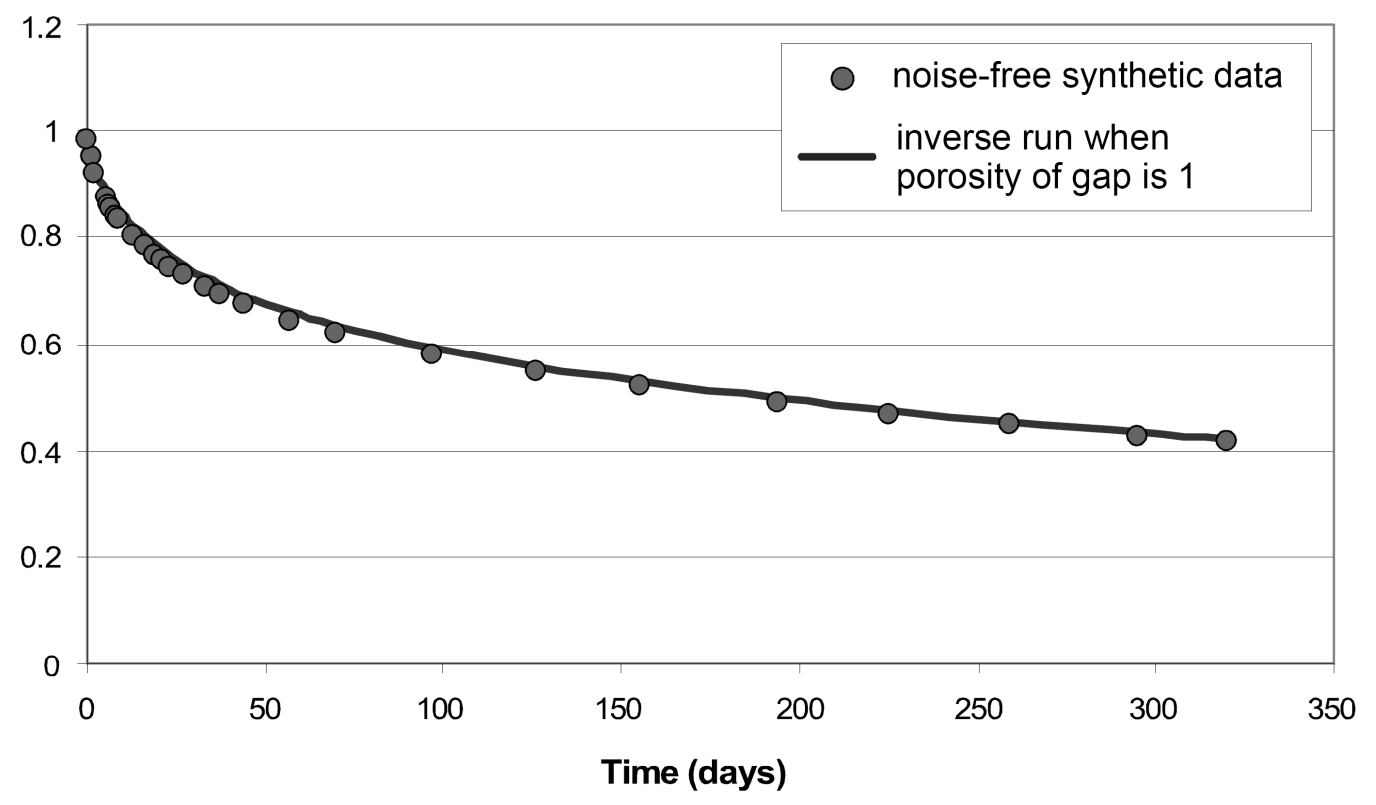

Figure 8 . Best fit to HTO noise-free synthetic data when the porosity of the gap is fixed equal to 1 . 


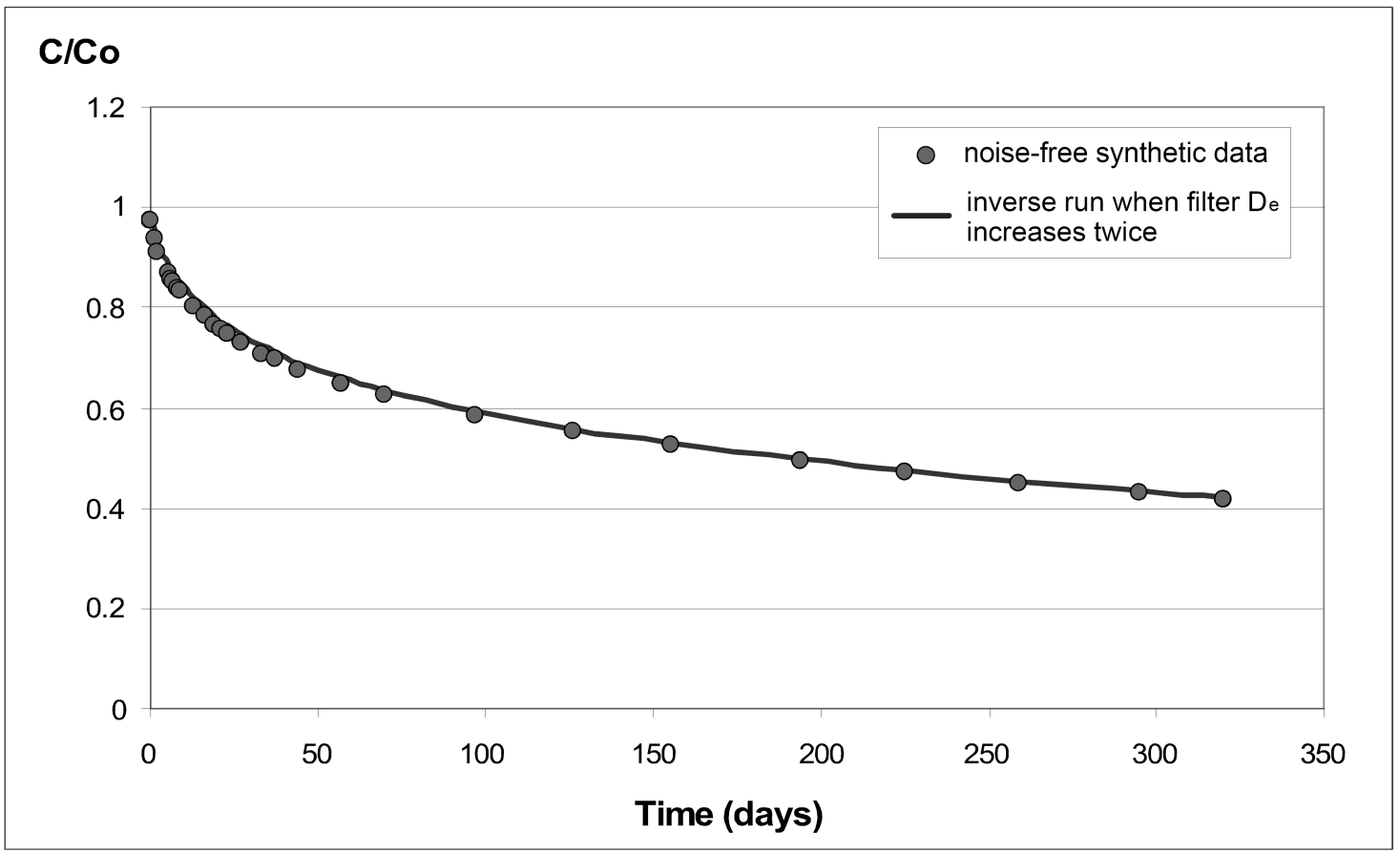

Figure 9. Best fit to HTO noise-free synthetic data when the $D_{e}$ of the filter is twice its reference value.

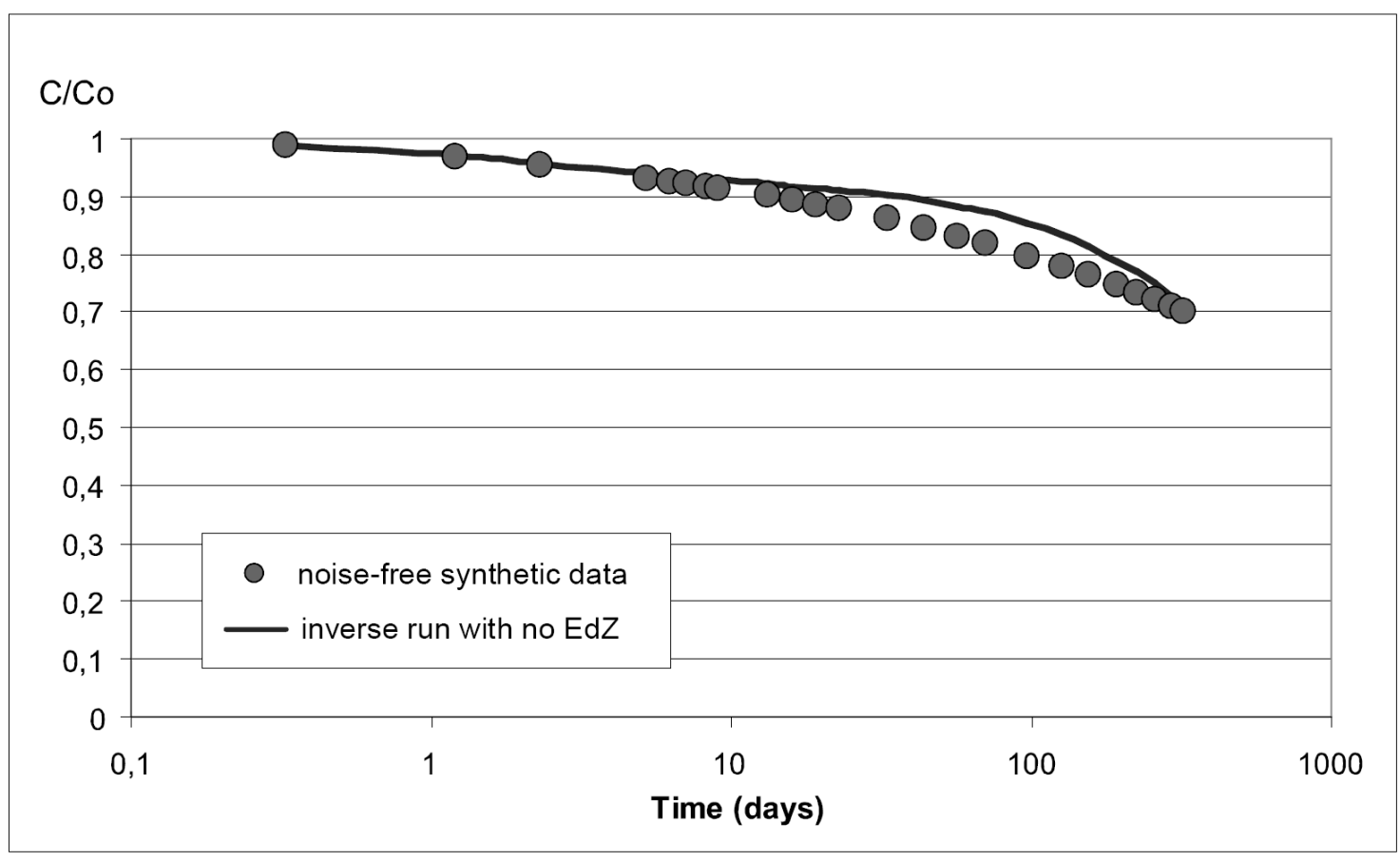

Figure 10. Model fit to ${ }^{36} \mathrm{Cl}^{-}$noise-free synthetic data for $\mathrm{EdZ}$ thickness equal to zero. 
Table 1. Reference values of diffusion and sorption parameters in different materials for all the tracers.

$D_{e}$ is the horizontal effective diffusion coefficient, $\Phi_{\text {acc }}$ is the accessible porosity and $K_{d}$ is the distribution coefficient.

\begin{tabular}{ccccccc} 
& & HTO & ${ }^{36} \mathbf{C l}^{-}$ & ${ }^{\mathbf{1 2 5}} \mathbf{I}^{-}$ & ${ }^{22} \mathbf{N a}^{+}$ & ${ }^{134} \mathbf{C s}^{+}$ \\
\hline \multirow{3}{*}{ Clay } & $\mathrm{D}_{\mathrm{e}}\left(\mathrm{m} / \mathrm{s}^{2}\right)$ & $4.1 \cdot 10^{-11}$ & $9.1 \cdot 10^{-12}$ & $4.4 \cdot 10^{-12}$ & $6.7 \cdot 10^{-11}$ & $3.6 \cdot 10^{-10}$ \\
& $\Phi_{\text {acc }}$ & 0.18 & 0.09 & 0.13 & 0.18 & 0.18 \\
& $\mathrm{~K}_{\mathrm{d}}(\mathrm{ml} / \mathrm{g})$ & --- & --- & --- & 0.74 & 50 \\
\hline \multirow{3}{*}{ EdZ } & $\mathrm{D}_{\mathrm{e}}\left(\mathrm{m} / \mathrm{s}^{2}\right)$ & $10^{-10}$ & $2.3 \cdot 10^{-11}$ & $1.1 \cdot 10^{-11}$ & $1.7 \cdot 10^{-10}$ & $9 \cdot 10^{-10}$ \\
& $\Phi_{\text {acc }}$ & 0.36 & 0.18 & 0.26 & 0.36 & 0.36 \\
& $\mathrm{~K}_{\mathrm{d}}(\mathrm{ml} / \mathrm{g})$ & --- & --- & --- & 0.74 & 50 \\
\hline \multirow{3}{*}{ Gap } & $\mathrm{D}_{\mathrm{e}}\left(\mathrm{m} / \mathrm{s}^{2}\right)$ & $2 \cdot 10^{-10}$ & $1.1 \cdot 10^{-10}$ & $3.4 \cdot 10^{-11}$ & $3.3 \cdot 10^{-10}$ & $1.8 \cdot 10^{-9}$ \\
& $\Phi_{\text {acc }}$ & 0.6 & 0.6 & 0.6 & 0.6 & 0.6 \\
& $\mathrm{~K}_{\mathrm{d}}(\mathrm{ml} / \mathrm{g})$ & --- & --- & --- & 0.74 & 50 \\
\hline \multirow{2}{*}{ Filter } & $\mathrm{D}_{\mathrm{e}}\left(\mathrm{m} / \mathrm{s}^{2}\right)$ & $8 \cdot 10^{-11}$ & $4.5 \cdot 10^{-11}$ & $1.3 \cdot 10^{-11}$ & $1.3 \cdot 10^{-10}$ & $7.1 \cdot 10^{-11}$ \\
& $\Phi_{\text {acc }}$ & 0.3 & 0.3 & 0.3 & 0.3 & 0.3 \\
\hline
\end{tabular}

Table 2. Computed relative sensitivities, $R S$, of tracer dilution curves to changes in parameters.

Cesium results are shown for two experiments in order to compare the variation of $R S$ with the experimental design.

\begin{tabular}{|c|c|c|c|c|c|c|c|}
\hline & & HTO & ${ }^{36} \mathrm{Cl}^{-}$ & ${ }^{125} \mathbf{I}^{-}$ & ${ }^{22} \mathrm{Na}^{+}$ & & \\
\hline & & DIR2001 & DIR2001 & DIR2001 & DIR2002 & DIR2002 & EST208 \\
\hline Total volume & $\Delta \mathrm{V}=-10 \%$ & 0.462 & 0.221 & 0.194 & 0.77 & 1.09 & 1.11 \\
\hline EdZ thickness & $\Delta \mathrm{e}=-2 \mathrm{~cm}$ & 0.124 & 0.072 & 0.055 & 0.21 & 0.387 & 0.344 \\
\hline & $\Delta \mathrm{e}=+2 \mathrm{~cm}$ & 0.074 & 0.038 & 0.012 & 0.082 & 0.018 & 0.016 \\
\hline Filter $D_{e}$ & $\Delta \mathrm{D}_{\mathrm{e}}>0$ & 0.014 & 0.018 & 0.012 & 0.033 & 0.053 & 0.049 \\
\hline & $\Delta \mathrm{D}_{\mathrm{e}}<0$ & 0.051 & 0.024 & 0.038 & 0.125 & 0.258 & 0.24 \\
\hline Gap D $D_{e}$ & $\Delta \mathrm{D}_{\mathrm{e}}>0$ & 0.014 & 0.014 & 0.003 & 0.011 & 0.026 & 0.025 \\
\hline & $\Delta \mathrm{D}_{\mathrm{e}}<0$ & 0.018 & 0.022 & 0.011 & 0.045 & 0.11 & 0.106 \\
\hline Gap $\Phi_{\text {acc }}$ & $\Delta \Phi_{\mathrm{acc}}>0$ & 0.061 & 0.051 & 0.02 & 0.03 & 0.063 & 0.071 \\
\hline & $\Delta \Phi_{\mathrm{acc}}<0$ & 0.071 & 0.062 & 0.033 & 0.031 & 0.071 & 0.076 \\
\hline$E_{d Z} D_{e}$ & $\Delta \mathrm{D}_{\mathrm{e}}>0$ & 0.034 & 0.016 & 0.022 & 0.089 & 0.22 & 0.334 \\
\hline & $\Delta \mathrm{D}_{\mathrm{e}}<0$ & 0.113 & 0.047 & 0.054 & 0.316 & 0.726 & 1.388 \\
\hline $\mathbf{E d Z} \Phi_{\mathrm{acc}}$ & $\Delta \Phi_{\mathrm{acc}}>0$ & 0.084 & 0.053 & 0.043 & 0.039 & 0.22 & 1.289 \\
\hline & $\Delta \Phi_{\mathrm{acc}}<0$ & 0.171 & 0.074 & 0.057 & 0.033 & 0.186 & 0.198 \\
\hline Clay $D_{e}$ & $\Delta \mathrm{D}_{\mathrm{e}}>0$ & 0.082 & 0.02 & 0.006 & 0.1 & 0.018 & 0.016 \\
\hline & $\Delta \mathrm{D}_{\mathrm{e}}<0$ & 0.143 & 0.031 & 0.010 & 0.197 & 0.033 & 0.03 \\
\hline Clay $\Phi_{\text {acc }}$ & $\Delta \Phi_{\mathrm{acc}}>0$ & 0.06 & 0.016 & 0.006 & 0.012 & 0.005 & 0.005 \\
\hline & $\Delta \Phi_{\mathrm{acc}}<0$ & 0.072 & 0.022 & 0.007 & 0.011 & 0.005 & 0.005 \\
\hline $\mathbf{K}_{\mathrm{d}}$ & $\Delta \mathrm{K}_{\mathrm{d}}>0$ & --- & --- & --- & 0.163 & 0.245 & 0.263 \\
\hline & $\Delta \mathrm{K}_{\mathrm{d}}<0$ & --- & --- & --- & 0.32 & 0.689 & 0.76 \\
\hline
\end{tabular}


Table 3. Summary of inverse runs in which effective diffusion coefficients, $D_{e}$, and accessible porosities, $\Phi_{\text {acc, }}$ of the undisturbed clay and of the EdZ are estimated for HTO.

(a) With the following prior information estimates for intact clay: effective diffusion $=4.1 \cdot 10^{-11} \mathrm{~m}^{2} /$ day and porosity $=0.18$. Weight given to prior information equal to 1 .

\begin{tabular}{|c|c|c|c|c|c|c|c|c|}
\hline \multirow[b]{2}{*}{$\begin{array}{c}\text { Standard } \\
\text { dev } \sigma\end{array}$} & \multicolumn{2}{|c|}{$\begin{array}{c}\text { Clay } D_{e} \\
\left(\mathbf{m}^{2} / \mathbf{s}\right)\end{array}$} & \multicolumn{2}{|c|}{ Clay $\Phi_{\text {acc }}$} & \multicolumn{2}{|c|}{$\begin{array}{c}\mathbf{E d Z} \mathbf{D}_{\mathrm{e}} \\
\left(\mathbf{m}^{2} / \mathbf{s}\right)\end{array}$} & \multicolumn{2}{|c|}{$\operatorname{EdZ} \Phi_{\text {acc }}$} \\
\hline & initial & estimated & initial & estimated & initial & estimated & initial & estimated \\
\hline 0.01 & $8.2 \cdot 10^{-11}$ & $3.6 \cdot 10^{-11}$ & - & - & - & - & - & - \\
\hline 0.05 & $8.2 \cdot 10^{-11}$ & $2.1 \cdot 10^{-11}$ & 0.36 & 0.36 & - & - & - & - \\
\hline 0.01 & - & - & - & - & $5.1 \cdot 10^{-11}$ & $2 \cdot 10^{-10}$ & 0.18 & 0.18 \\
\hline 0.01 & $2.1 \cdot 10^{-11}$ & $3 \cdot 10^{-11}$ & 0.09 & 0.28 & $5.1 \cdot 10^{-11}$ & $1.4 \cdot 10^{-10}$ & 0.54 & 0.29 \\
\hline 0.01 & $8.1 \cdot 10^{-11}$ & $4.1 \cdot 10^{-11}$ & 0.36 & 0.13 & $2.1 \cdot 10^{-10}$ & $1.1 \cdot 10^{-10}$ & 0.54 & 0.35 \\
\hline 0.05 & $2.1 \cdot 10^{-11}$ & $2.1 \cdot 10^{-11}$ & 0.09 & 0.36 & $5.1 \cdot 10^{-11}$ & $7.9 \cdot 10^{-10}$ & 0.54 & 0.18 \\
\hline 0.05 & $8.1 \cdot 10^{-11}$ & $3.2 \cdot 10^{-11}$ & 0.36 & 0.15 & $2.1 \cdot 10^{-10}$ & $1.7 \cdot 10^{-10}$ & 0.54 & 0.32 \\
\hline 0.05 & $8.1 \cdot 10^{-11}$ & $\left(^{a}\right) 3.7 \cdot 10^{-11}$ & 0.25 & $\left(^{a}\right) 0.24$ & - & - & - & - \\
\hline 0.05 & $8.1 \cdot 10^{-11}$ & ( $\left.^{\mathrm{a}}\right) 3.4 \cdot 10^{-11}$ & 0.25 & $\left(^{a}\right) 0.21$ & $2 \cdot 10^{-10}$ & $9.8 \cdot 10^{-11}$ & 0.56 & 0.55 \\
\hline $\begin{array}{l}\text { True } \\
\text { value }\end{array}$ & & $4.1 \cdot 10^{-11}$ & & 0.18 & & $10^{-10}$ & & 0.36 \\
\hline
\end{tabular}

Table 4. Summary of inverse runs in which effective diffusion coefficient, $D_{e}$, and accessible porosity, $\Phi_{\text {acc, }}$ of the undisturbed clay and of the EdZ are estimated for HTO in order to study the relevance of uncertainties in the thickness of the EdZ, the volume of the water in the injection system, the porosity of the gap and the diffusion coefficient of the filter.

\begin{tabular}{|c|c|c|c|c|c|c|c|c|c|}
\hline \multirow[b]{2}{*}{ Hypothesis } & \multicolumn{2}{|c|}{$\begin{array}{c}\text { Clay } D_{e} \\
\left(\mathrm{~m}^{2} / \mathrm{s}\right)\end{array}$} & \multicolumn{2}{|c|}{ Clay $\Phi_{\text {acc }}$} & \multicolumn{2}{|c|}{$\begin{array}{c}\operatorname{EdZ} D_{e} \\
\left(\mathrm{~m}^{2} / \mathrm{s}\right)\end{array}$} & \multicolumn{2}{|c|}{$\operatorname{EdZ} \Phi_{\mathrm{acc}}$} & \multirow[b]{2}{*}{$\boldsymbol{\sigma}$} \\
\hline & initial & estimated & initial & estimated & Initial & estimated & initial & estimated & \\
\hline \multirow{2}{*}{ No EdZ } & $8.1 \cdot 10^{-11}$ & $8.1 \cdot 10^{-11}$ & 0.25 & 0.24 & - & - & - & - & 0 \\
\hline & $2.1 \cdot 10^{-11}$ & $5 \cdot 10^{-11}$ & 0.09 & 0.1 & - & - & - & - & 0 \\
\hline \multirow{2}{*}{$\begin{array}{c}5 \% \text { smaller } \\
\text { water volume }\end{array}$} & $8.1 \cdot 10^{-11}$ & $5 \cdot 10^{-11}$ & 0.25 & 0.09 & - & - & - & - & 0 \\
\hline & $8.1 \cdot 10^{-11}$ & $4.4 \cdot 10^{-11}$ & 0.25 & 0.1 & - & - & - & - & 0.05 \\
\hline \multirow{3}{*}{$\begin{array}{l}\text { Porosity of gap } \\
\quad \text { equal } 1\end{array}$} & $4.1 \cdot 10^{-11}$ & $3.9 \cdot 10^{-11}$ & 0.18 & 0.23 & $10^{-10}$ & $7.4 \cdot 10^{-11}$ & 0.36 & 0.36 & 0 \\
\hline & $2.1 \cdot 10^{-11}$ & $3.1 \cdot 10^{-11}$ & 0.09 & 0.35 & $5.1 \cdot 10^{-11}$ & $1.4 \cdot 10^{-10}$ & 0.18 & 0.18 & 0 \\
\hline & $8.1 \cdot 10^{-11}$ & $3 \cdot 10^{-11}$ & 0.36 & 0.36 & $2.1 \cdot 10^{-11}$ & $1.2 \cdot 10^{-11}$ & 0.56 & 0.25 & 0 \\
\hline \multirow{3}{*}{$\begin{array}{c}\mathrm{D}_{\mathrm{e}} \text { of filter }= \\
\text { two times } \\
\text { reference value }\end{array}$} & $4.1 \cdot 10^{-11}$ & $3.9 \cdot 10^{-11}$ & 0.18 & 0.23 & $10^{-10}$ & $7.4 \cdot 10^{-11}$ & 0.36 & 0.37 & 0 \\
\hline & $2.1 \cdot 10^{-11}$ & $2.9 \cdot 10^{-11}$ & 0.09 & 0.29 & $5.1 \cdot 10^{-11}$ & $1.4 \cdot 10^{-10}$ & 0.18 & 0.18 & 0 \\
\hline & $8.1 \cdot 10^{-11}$ & $3 \cdot 10^{-11}$ & 0.36 & 0.36 & $2.1 \cdot 10^{-11}$ & $1.2 \cdot 10^{-11}$ & 0.56 & 0.25 & 0 \\
\hline True value & & $4.1 \cdot 10^{-11}$ & & 0.18 & & $10^{-10}$ & & 0.36 & \\
\hline
\end{tabular}


Table 5. Summary of inverse runs in which effective diffusion, $D_{e}$, and accessible porosity, $\Phi_{\text {acc}}$, of the undisturbed clay and of the $\mathrm{EdZ}$ are estimated for ${ }^{36} \mathrm{Cl}^{-}$.

\begin{tabular}{|c|c|c|c|c|c|c|c|c|}
\hline \multirow[b]{2}{*}{$\begin{array}{c}\text { Standard } \\
\operatorname{dev} \sigma\end{array}$} & \multicolumn{2}{|c|}{$\begin{array}{c}\text { Clay } D_{e} \\
\left(\mathbf{m}^{2} / s\right)\end{array}$} & \multicolumn{2}{|c|}{ Clay $\Phi_{\text {acc }}$} & \multicolumn{2}{|c|}{$\begin{array}{c}\mathbf{E d Z} D_{\mathrm{e}} \\
\left(\mathrm{m}^{2} / \mathrm{s}\right)\end{array}$} & \multicolumn{2}{|c|}{$\operatorname{EdZ} \Phi_{\text {acc }}$} \\
\hline & initial & estimated & initial & estimated & initial & estimated & initial & estimated \\
\hline 0.02 & $1.9 \cdot 10^{-11}$ & $1.6 \cdot 10^{-12}$ & 0.15 & 0.04 & - & - & - & - \\
\hline 0.02 & - & - & - & - & $4.5 \cdot 10^{-11}$ & $2.3 \cdot 10^{-11}$ & 0.36 & 0.19 \\
\hline 0.02 & $1.9 \cdot 10^{-11}$ & $1 \cdot 10^{-11}$ & - & - & $4.5 \cdot 10^{-11}$ & $2.3 \cdot 10^{-11}$ & - & - \\
\hline 0.02 & - & - & 0.05 & 0.11 & - & - & 0.12 & 0.18 \\
\hline 0.02 & $4.5 \cdot 10^{-12}$ & $1.3 \cdot 10^{-10}$ & 0.05 & 0.04 & $1.1 \cdot 10^{-11}$ & $1.5 \cdot 10^{-9}$ & 0.09 & 0.27 \\
\hline 0.02 & $1.9 \cdot 10^{-11}$ & $1.3 \cdot 10^{-10}$ & 0.12 & 0.04 & $4.5 \cdot 10^{-11}$ & $7.9 \cdot 10^{-12}$ & 0.26 & 0.56 \\
\hline $\begin{array}{l}\text { True } \\
\text { value }\end{array}$ & & $9.1 \cdot 10^{-12}$ & & 0.09 & & $2.3 \cdot 10^{-11}$ & & 0.18 \\
\hline
\end{tabular}

Table 6. Summary of inverse runs in which effective diffusion coefficient, $\mathrm{D}_{\mathrm{e}}$, and accessible porosity, $\Phi_{\text {acc }}$, of undisturbed clay and $\mathrm{EdZ}$ are estimated for ${ }^{36} \mathrm{Cl}^{-}$in order to study the relevance of uncertainties related to the thickness of the EdZ, the volume of the water in the injection system, the porosity of the gap and the diffusion coefficient of the filter.

\begin{tabular}{|c|c|c|c|c|c|}
\hline \multirow[b]{2}{*}{ Hypothesis } & \multicolumn{2}{|c|}{$\begin{array}{c}\text { Clay } D_{e} \\
\left(\mathrm{~m}^{2} / \mathbf{s}\right)\end{array}$} & \multicolumn{2}{|c|}{ Clay $\Phi_{\text {acc }}$} & \multirow[b]{2}{*}{$\sigma$} \\
\hline & initial & estimated & initial & estimated & \\
\hline \multirow{2}{*}{ No EdZ } & $4.5 \cdot 10^{-12}$ & $10^{-10}$ & 0.05 & 0.36 & 0 \\
\hline & $1.9 \cdot 10^{-11}$ & $10^{-10}$ & 0.18 & 0.36 & 0 \\
\hline \multirow{3}{*}{$\begin{array}{l}\text { Total volume } \\
5 \% \text { smaller }\end{array}$} & $4.5 \cdot 10^{-12}$ & $9.1 \cdot 10^{-12}$ & 0.05 & 0.089 & 0 \\
\hline & $4.5 \cdot 10^{-12}$ & $9.8 \cdot 10^{-12}$ & 0.05 & 0.12 & 0.02 \\
\hline & $1.9 \cdot 10^{-11}$ & $1.3 \cdot 10^{-11}$ & 0.15 & 0.06 & 0.02 \\
\hline \multirow{2}{*}{ Porosity of gap equal 1} & $4.5 \cdot 10^{-12}$ & $3.9 \cdot 10^{-12}$ & 0.05 & 0.17 & 0 \\
\hline & $1.9 \cdot 10^{-11}$ & $7.9 \cdot 10^{-12}$ & 0.18 & 0.05 & 0 \\
\hline \multirow{2}{*}{$\begin{array}{l}\mathrm{D}_{\mathrm{e}} \text { of filter two times } \\
\text { reference one }\end{array}$} & $4.5 \cdot 10^{-12}$ & $2.8 \cdot 10^{-12}$ & 0.05 & 0.38 & 0 \\
\hline & $1.9 \cdot 10^{-11}$ & $1.4 \cdot 10^{-11}$ & 0.18 & 0.05 & 0 \\
\hline True value & & $9.1 \cdot 10^{-12}$ & & 0.09 & \\
\hline
\end{tabular}

